region in 1974) the scanner could remove the fear that a treatable lesion may be missed or recognised too late.

This is of particular interest at a time when high-cost technology medicine requires justification. Fineberg et al $^{4}$ proposed standards by which a new piece of medical technology should be judged, and his criteria have been developed and adopted by the American Medical Association for its policy on CAT scanning. There are five levels of efficiency: (a) technical capability, whether the apparatus provides an accurate representation of the area scanned; (b) diagnostic accuracy, whether it provides information that contributes to a correct diagnosis (c) diagnostic impact, the extent to which CAT scanning replaces other diagnostic procedures; $(d)$ therapeutic impact, the change in management that would not have taken place without information from the scan; and (e) outcome, the effect of CAT scan information on patient morbidity and mortality.

Undoubtedly the scanner satisfies the first three criteria, and in the care of those with head injuries there are good grounds for believing that treatment and outcome in many cases may be largely determined by the scan findings.

\section{ADMINISTRATIVE AND ECONOMIC FACTORS}

Some cost implications may be observed from the analysis of the reduced radiological work load correlated with the catchment population.

Table IV shows the requirements of the special units for contrast radiology in 1974 and the effect that the introduction of a CAT scanner had on the work loads in the specialist rooms. The reductions of $50 \%$ for angiography and $90 \%$ for air studies were taken as minimum, on the basis of this series and other observations. ${ }^{15-7}$ The percentage use was calculated from an estimate of the maximum capacity for each room ${ }^{5}$ and tested against that achieved at Brook General Hospital during 1974.

The spare capacity of the equipment indicates that one neuroradiology department could provide the service for about four million people. Therefore, if the number of departments of neuroradiology could be reduced over several years money would be saved. Some of this money could be spent on placing scanners in general hospitals, where ready access to this tool would improve the local service, particularly in managing patients with head injuries, and also reduce the number of patients who require transfer to the central unit for specialist investigation and treatment.

The debate about high-cost medicine should take into account the level of use, clinical efficiency judged by economic criteria, and the relationships that the technology has to the other aspects of the service. The high cost of a piece of equipment alone does not justify centralisation.

\section{References}

1 Thomson, J L G, Health Trends, 1977, 9, 16

2 Paxton, R, and Ambrose, J, British fournal of Radiology, 1974, 47, 530.

${ }^{3}$ Ambrose, J, Gooding, M R, and Uttley, D, Lancet, 1976, 1, 847.

${ }^{4}$ Fineberg, H V, Bauman, R, and Sosman, M, fournal of the American Medical Association, 1977, 238, 224.

5 Jonesson, E, and Marke, L A, Health Care Management Review, 1977, $2,37$.

6 Wortzman, G, Holgate, R C, and Morgan, P P, Radiology, 1975, 117, 75

${ }^{7}$ Buerger, R E, and Huchman, M, Computed Tomography Survey. Chicago, Illinois, Rush Presbyterian St Luke Medical Centre, 1975.

(Accepted 26 fuly 1978)

\title{
Evaluating cost-effectiveness of diagnostic equipment: the brain scanner case
}

\author{
J R BARTLETT, G NEIL-DWYER, J M M BANHAM， D G CRUICKSHANK
}

British Medical fournal, 1978, 2, 815-820

\section{Summary and conclusions}

An approach to evaluating the cost-effectiveness of hightechnology diagnostic equipment has been devised, using the introduction of computerised axial tomography (CAT) as a model. With the advent of CAT scanning, angiography and air encephalography have a reduced, though important, role in investigating intracranial disease, and the efficient use of conventional equipment requires the centralisation of neuroradiological services, which would result in major cash savings. In contrast, the pattern of demand for CAT scanning, in addition to the acknowledged clinical efficiency of the scanner and its

Brook General Hospital, London SE18

J R BARTLETT, FRCs, consultant neurosurgeon

G NEIL-DWYER, FRCS, consultant neurosurgeon

McKinsey and Co, London

J M M BANHAM, MA, principal

D G CRUICKSHANK, CA (now commercial director, Times Newspapers) unique role in the head-injured patient, ephasises the need for improved access to scanners. In the interest of the patients the pattern of service must change.

\section{Introduction}

The cost of introducing computerised axial tomography (CAT) scanners into a neuroradiological service is high. Justification for this expenditure is particularly important at a time when there is widespread concern at the escalating costs of health care.

There are three aspects to the economic case for any piece of medical equipment : firstly, the effect on existing procedures and equipment-in this case the large reduction in demand for angiograms and encephalograms; secondly, the effect of the new equipment on existing services-a fall in demand for conventional neuroradiology raises the possibility that fewer departments could serve the population; and, finally, the reduction in morbidity and mortality that takes place as a result of introducing the equipment. We show here how all three aspects can be taken into account and describe an approach to evaluating the cost of CAT scanning of the brain that could also be applied to other medical equipment. The analysis consists in (a) assessing the likely demand for brain scanning and other neuroradiological services in an NHS region; $(b)$ identifying 
alternative ways of meeting the demand; $(c)$ assessing the cost implications of the alternatives and identifying the option that provides the best "return" to the community, assuming that patient outcome is not affected; and $(d)$ assessing the value of improved treatment.

\section{Assessing demand for neuroradiology and brain scanning}

An EMI brain scanner was installed in the neurosurgical unit at the Brook General Hospital in south London in February 1976. Experience since then provided a guide to changes in demand for both conventional neuroradiological procedures and brain scanning (see accompanying paper).

\section{CONVENTIONAL NEURORADIOLOGY}

Table I shows the profile, before scanners were introduced, of neurosurgery, neurology, and accident services for a population of about 3.6 million people in the South-east Thames region. The introduction of CAT scanning for the immediate needs of a specialist unit reduces the need for angiograms by $50 \%$ and for air studies by $90 \% .{ }^{1-3}$ Experience at the Brook General Hospital confirmed these findings. We estimated therefore that if neurosurgeons and neurologists had adequate access to scanners regional demand for angiograms would not exceed 1500 and the number of air studies required would fall to about 90 .

\section{BRAIN SCANNING}

We assessed the demand for brain scanning in two ways, firstly by examining the demand made on a CAT scanner after installation at one hospital and calculating demand throughout the region, and, secondly, by examining the different types of demand-for example, for diagnosis, planning management-made by different specialties.

Demand after installation-(1) Demand from neurosurgical and neurological departments was calculated from the number of patients scanned at the Brook General Hospital and the hospital's catchment population. (2) Demand from accident departments was calculated on the assumption that half the 4800 people admitted for observation after a head injury throughout the region (1974 figures) would undergo scanning if facilities were available. (3) We estimated that 0.04 people per 1000 would be scanned for ophthalmology and ear, nose, and throat departments. ${ }^{4}$ A figure of 0.6 people per 1000 was calculated as the demand for scanning generated by other specialties. This figure assumed a local catchment population for the Brook General Hospital of 100000 . Table II shows that on the basis of these calculations 2 people per 1000 per year would undergo scanning if adequate equipment were available. Table II assumes that scanners would be located in specialist units and certain district general hospitals, where there would be special access for major accident departments and qualified access for other departments. It also assumes that some cases investigated by neurologists would be examined at district hospitals. This approach makes no assessment of the clinical utility of the findings.

Demands for different purposes-Using the figures for each specialty shown in table II, fig 1 shows (approximately) the purpose for which each specialty would use the scanner. In many cases a patient's diagnosis is clear, but information from the scanner is essential for
TABLE II-Patients to be investigated by brain scanner per 1000 population served

\begin{tabular}{l|c|c|c}
\hline \multirow{2}{*}{ Origin of requests } & Special unit & Scanner location \\
\cline { 2 - 4 } & 0.38 & District hospitals \\
\hline $\begin{array}{l}\text { Neurosurgery } \\
\text { Acurology } \\
\text { Allied spect access } \\
\text { (ENT, ophthalmology) }\end{array}$ & $\begin{array}{c}\text { Accident unit } \\
\text { (head injuries) }\end{array}$ \\
\hline \begin{tabular}{l} 
Others \\
\hline
\end{tabular} & 0.38 & 0.64 \\
\hline
\end{tabular}

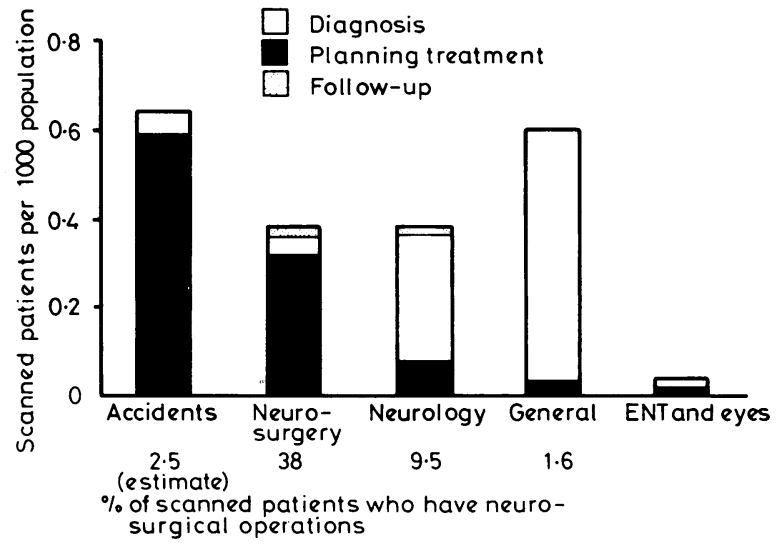

FIG 1-Role of scanner in each specialty.

planning treatment. For instance, information from the scanner was used for planning treatment in roughly $85 \%$ of neurosurgical cases ; and nearly $40 \%$ of patients scanned were operated on-often with no further special tests. This is in strong contrast to many general requests, where the purpose is to confirm the clinical diagnosis of, or perhaps exclude, a tumour. Those who want to satisfy this demand argue that accurate diagnosis is an indispensable prelude to management. But accurate interpretation of the scan often depends on the clinical facts. An advanced (and expensive) test should not replace clinical skills. The scanner has a unique role in the management of head injury. By showing the nature of the intracranial event for those responsible for initial care, the scanner would remove the fear that a treatable lesion may be missed or recognised too late. For this reason most scans done in accident departments would determine management. Therefore, about half the total demand for scans-one patient per 1000 population per annum-would be needed to satisfy the requirements of patient management.

Thus, on the basis of experience at the Brook General Hospital, about 1.4 patients per 1000 population would need to be scanned annually by neurosurgery, neurology, and accident departments; and other specialists requesting brain scans would increase the demand to perhaps 2.0 patients a year. American experience indicates that in $70 \%$ of cases contrast media are used after the original scan. So total

TABLE I-Profile of neurosurgical, neurological, and accident services in South-east Thames region* before introduction of scanner

\begin{tabular}{|c|c|c|c|c|c|c|c|c|c|c|c|c|c|c|c|}
\hline Hospital: & 1 & 2 & 3 & 4 & 5 & 6 & 7 & 8 & 9 & 10 & 11 & 12 & 13 & 14 & Total \\
\hline $\begin{array}{l}\text { Neurosurgery: } \\
\text { Beds } \\
\text { Cases } \\
\text { Neurology: } \\
\text { Beds } \\
\text { Cases } \\
\text { Neuroradiology } \\
\text { Accident centres } \\
\text { Angiograms } \\
\text { Encephalograms } \\
\text { Other tests }\end{array}$ & $\begin{array}{r}58 \\
1160 \\
36 \\
305 \\
+ \\
+ \\
1200 \\
350 \\
290\end{array}$ & $\begin{array}{r}42 \\
840 \\
36 \\
805 \\
+ \\
1000 \\
300 \\
270\end{array}$ & $\begin{array}{c}17 \\
384 \\
+ \\
+ \\
230 \\
70 \\
20\end{array}$ & $\begin{array}{r}20 \\
447 \\
+ \\
+ \\
270 \\
80 \\
40\end{array}$ & $\begin{array}{c}25 \\
559 \\
+ \\
+ \\
300 \\
100 \\
80\end{array}$ & & + & + & + & + & + & + & + & + & $\begin{array}{r}100 \\
2000 \\
134 \\
3000 \\
\\
3000 \\
900 \\
700\end{array}$ \\
\hline
\end{tabular}

*Estimates based on SH3 returns and records from Brook General Hospital. 
demand for scans would be from 2.5 to 3.5 scans per 1000 population, depending on how the scanner is used. A rise above 3.5 scans per 1000 population per year would suggest that some investigations had no bearing on management or outcome. Deployment of sufficient scanners to ensure scanning of those patients whose treatment is determined by the findings would produce spare capacity.

Three additional factors may increase demand above the level experienced at the Brook General Hospital: a profession educated to place a particularly high value on investigative techniques; an excessive burden of legal responsibility for clinical error and the need to practise defensive medicine; and a public educated to believe that machines diagnose and that accurate diagnosis is an essential prelude to good treatment. Many illnesses are diagnosed retrospectively or not at all, yet patients recover.

\section{Alternative ways of meeting the demand}

The range of possible annual demand for brain scans (2.5-3.5 scans per 1000 population) means that the South-east Thames region with a population of 3.6 million would generate demand for 9000 to 12500 brain scans a year, given that the access policies applied at the Brook General Hospital were applied generally. Each brain scanner should be able to perform at least 2750 scans a year, which means that three to four brain scanners would be fully used. Where should these scanners be located? And what changes should be made to existing neuroradiological services? These questions need answering in the light of general, regional, and local considerations. Several other questions therefore emerge.

(1) Should scanners be limited to the major specialist neurosurgical and neurological units?

(2) Should scanning be made available to the major accident services? And should all head-injured patients be admitted only to places equipped with scanners? This assumes that people can be trained to use the scanner and that it will have an effect on patient morbidity and mortality. As accidents commonly affect young healthy people, this question is one of great economic importance.

(3) Should the impact of scanners on neuroradiology lead to closure of any departments? If so, what are the savings? This question is partly general because the introduction of scanning potentially doubles the population that a single neuroradiological department can serve.

(4) Are there local problems that affect the efficient use of new equipment and the way existing services can be altered?

TABLE III-Fixed (capital) cost per study in neuroradiology departments in South-east Thames region after introduction of brain scanners

\begin{tabular}{|c|c|c|c|c|c|}
\hline Unit: & 1 & 2 & 3 & 4 & 5 \\
\hline $\begin{array}{l}\text { Angiograms: } \\
\text { Cost per study }(£) \\
\text { Utilisation }(\%)\end{array}$ & $\begin{array}{l}12 \\
39\end{array}$ & $\begin{array}{l}14 \\
33\end{array}$ & $\begin{array}{r}61 \\
8\end{array}$ & $\begin{array}{r}52 \\
9\end{array}$ & $\begin{array}{l}41 \\
11\end{array}$ \\
\hline $\begin{array}{l}\text { Air studies: } \\
\text { Cost per study }(£) \\
\text { Utilisation }(\%)\end{array}$ & $\begin{array}{r}670 \\
5\end{array}$ & $\begin{array}{r}780 \\
4\end{array}$ & $\begin{array}{r}3357 \\
1\end{array}$ & $\begin{array}{r}2937 \\
1\end{array}$ & $\begin{array}{r}2350 \\
2\end{array}$ \\
\hline
\end{tabular}

Based on current capital costs only and assuming a 10-year equipment life.

\section{CHANGING EXISTING SERVICES}

In 1976-7 a conventional neuroradiological unit cost about $£ 550000$ to establish. Such expensive equipment demands a high rate of use. With the post-scanner reduction in demand for conventional neuroradiology, two rooms for angiography and one for air studies could meet the need for these investigations for the entire region. Apart from the cost, the benefits of concentrating neuroradiology in one or two departments include: 24-hour cover, the availability of special skills, and an environment suitable for teaching and research. But concentrating neuroradiological services in this way would mean that existing $x$-ray departments were separated from operating theatres and the clinicians primarily responsible for patients. And this is not feasible. Table III shows the likely costs of studies performed in the five existing neuroradiology units after the introduction of scanning. Use is likely to be low, and the cost of each study would therefore be high.

To illustrate our approach to economic analysis, we identified three options for deploying scanners throughout the South-east Thames region. Table I shows the existing numbers of neurological and neurosurgical beds in the region and the location of the five neuroradiological units. Four scanners - two head scanners and two general purpose systems-are already in use in the region.

\section{Options}

The options (table IV) are described below.

Option 1-Head scanners would be introduced into all major neurosurgical and neurological units. Scanners would be introduced into two additional hospitals, and several accident departments would have some access to scanning.

Option 2-Head scanners would be introduced into all major neurosurgical units and into hospitals with neurological units, and smaller departments of neuroradiology that are separate from the two main neurosurgical units would be closed. Only small savings would follow the closures because some facilities-such as clean screening and specialist tomography-would still be needed in these comprehensive hospitals. The extra cost of maintaining angiography is marginal, and the savings would be limited. Finally, closure of the main diagnostic support facilities for neurology beds implies that new accommodation for patients requiring angiography, air studies, and perhaps myelography would be necessary within the two units with the major diagnostic facilities. Large capital sums would be required to implement these changes.

Option 3-Scanners would be introduced into selected district hospitals where all head injury services would be centred. Neuroradiology continues at five centres. This option accepts the pattern of local centralisation of major accident services. Already two major accident services each take most head-injured patients from populations approaching half a million. The number of cases of craniocerebral trauma requiring transfer to neurosurgical units would fall by about half (data to be published).

Finally, some patients at present travelling to the main units for investigations could be assessed locally by visiting staff.

These options are not exhaustive. One of the neurosurgical units is

TABLE IV-Options for using scanners in one NHS region

\begin{tabular}{|c|c|c|c|c|c|c|c|c|c|c|c|c|c|c|c|}
\hline Hospital: & 1 & 2 & 3 & 4 & 5 & 6 & 7 & 8 & 9 & 10 & 11 & 12 & 13 & Total & Present \\
\hline \multicolumn{16}{|c|}{ Option 1} \\
\hline $\begin{array}{l}\text { Neurosurgery (beds) } \\
\text { Neurology (beds) } \\
\text { Accident centres* } \\
\text { Neuroradiology } \\
\text { Scanners }\end{array}$ & $\begin{array}{l}58 \\
36 \\
+ \\
+ \\
+\end{array}$ & $\begin{array}{l}42 \\
36 \\
+ \\
+\end{array}$ & $\begin{array}{l}17 \\
+ \\
+ \\
+\end{array}$ & $\begin{array}{l}20 \\
+ \\
+ \\
+\end{array}$ & $\begin{array}{l}25 \\
+ \\
+ \\
+\end{array}$ & + & + & & + & + & + & & & $\begin{array}{r}100 \\
134 \\
8 \\
5 \\
6\end{array}$ & $\begin{array}{r}100 \\
134 \\
8 \\
5 \\
4\end{array}$ \\
\hline $\begin{array}{l}\text { Neurosurgery (beds) } \\
\text { Neurology (beds) } \\
\text { Accident centres* } \\
\text { Neuroradiology } \\
\text { Scanners }\end{array}$ & $\begin{array}{l}58 \\
36 \\
+ \\
+ \\
+\end{array}$ & $\begin{array}{l}42 \\
36 \\
+ \\
+ \\
+\end{array}$ & $\begin{array}{l}17 \\
+ \\
+\end{array}$ & $\begin{array}{l}20 \\
+ \\
+\end{array}$ & $\begin{array}{l}25 \\
+ \\
+\end{array}$ & + & + & & + & + & + & & & $\begin{array}{r}100 \\
134 \\
8 \\
2 \\
6\end{array}$ & $\begin{array}{r}100 \\
134 \\
8 \\
5 \\
4\end{array}$ \\
\hline \multicolumn{16}{|c|}{ Option 3} \\
\hline $\begin{array}{l}\text { Neurosurgery (beds) } \\
\text { Neurology (beds) } \\
\text { Accident centres* } \\
\text { Neuroradiology } \\
\text { Scanners }\end{array}$ & $\begin{array}{l}58 \\
36 \\
+ \\
+ \\
+\end{array}$ & $\begin{array}{l}42 \\
36 \\
+ \\
+\end{array}$ & $\begin{array}{l}17 \\
+ \\
+ \\
+\end{array}$ & $\begin{array}{l}20 \\
+ \\
+ \\
+\end{array}$ & $\begin{array}{l}25 \\
+ \\
+ \\
+\end{array}$ & $\begin{array}{l}+ \\
+\end{array}$ & $\begin{array}{l}+ \\
+\end{array}$ & & & $\begin{array}{l}+ \\
+\end{array}$ & $\begin{array}{l}+ \\
+\end{array}$ & & & $\begin{array}{r}100 \\
134 \\
8 \\
5 \\
9\end{array}$ & $\begin{array}{r}100 \\
134 \\
8 \\
5 \\
4\end{array}$ \\
\hline
\end{tabular}

*Major units. 
in an area where two new enlarged district general hospitals have just been completed. There may be enough beds in these hospitals, together with those of a small community hospital, to serve the population. It is therefore reasonable to consider relocation of the regional units which are at present situated in old buildings. Specific questions then arise: (a) should several small units be fused into one department? (b) Should a unit or units be relocated to make better use of the natural communications ? (c) If a unit or units are relocated can the receiving hospital provide the necessary support services ? $(d)$ Can benefits brought by the special units to the receiving hospital be used efficiently? Answers to these questions may have great consequences for the cost of a service and affect decisions that concern the purchase and location of several scanners.

The practical effect of these questions can be seen in two further options now being discussed in the region.

Option 4-The regional units would be transferred into a comprehensive hospital. The hospital which has adequate and appropriate support facilities and could use efficiently the benefits brought by the special unit has poor road communications. One complete department of neuroradiology would close. The capital cost of transfer must be set against the revenue savings and the time taken for realisation.

Option 5-The regional units would be transferred to the site of one of the recently completed hospitals. This option places the unit on a good open site with excellent road communications. The existing hospital could not use the full benefits brought by the specialist unit because it does not have all the important related specialties. But there is sufficient land to bring these specialties to this site. Major new building would be required as well as redeployment of other important services. All five departments of neuroradiology would be retained. The cost of the new buildings and the present lack of support service for clinical efficiency must be balanced against the convenience of the road communications.

In both versions scanners would be introduced into major accident centres.

\section{Assessing cost of options}

There are at least three different approaches to costing the options defined above.

Cost accounting seeks to answer the question: Is the unit cost of a brain scan less than the cost of the test that it replaces? The answer is clearly yes. ${ }^{12}$ A study by the Swedish Planning and Rationalisation Institute for Health Care and Social Security (SPRI) showed that the ratio of costs of brain scanning, angiography, and pneumoencephalography was $1: 7: 11 .^{2}$ This approach may be valid for cost control purposes after policy is settled, for assumptions are made about use of equipment, staff, and overheads that may not reflect what is possible. For example, the $1: 7: 11$ ratio quoted above assumes that a unit will do 1500 angiograms and 750 pneumoencephalograms per annumfigures that are never achieved in the UK.

Service accounting examines the total costs of a specialist service and the effect that the introduction of a particular piece of equipment has on this service. Policies based on this approach are feasible for developing a new service. In a developed and complex health service, such as the NHS, however, it is difficult to implement change. Expenditure which has been based on this approach often fails to produce the predicted savings because the other changes on which the savings depend do not materialise. None the less, the approach defines the necessary changes to achieve the long-term aim of more effective health care.

Cash flow-This means (a) assessing the cash costs at today's prices and costs of installing scanners, as proposed in the options, and their likely phasing; (b) calculating potential savings from installing scanners, again in cash terms in today's money; and (c) calculating the value today (net present value) of the future savings or costs, taking into account the likelihood that the potential savings will be realised.

We selected the cash flow approach since it permits comparisons between the options on the basis of cost. Inevitably important elements in the cost equations are estimates but for the purpose of this paper the method of analysis is as important es the conclusion.

\section{THE COSTS OF CAT SCANNING}

The costs of CAT scanning have been documented fairly rigorously in the United Kingdom, North America, and Sweden. In cash terms (ignoring "notional" costs, such as depreciation) the following costs will be incurred (fig 2 ).

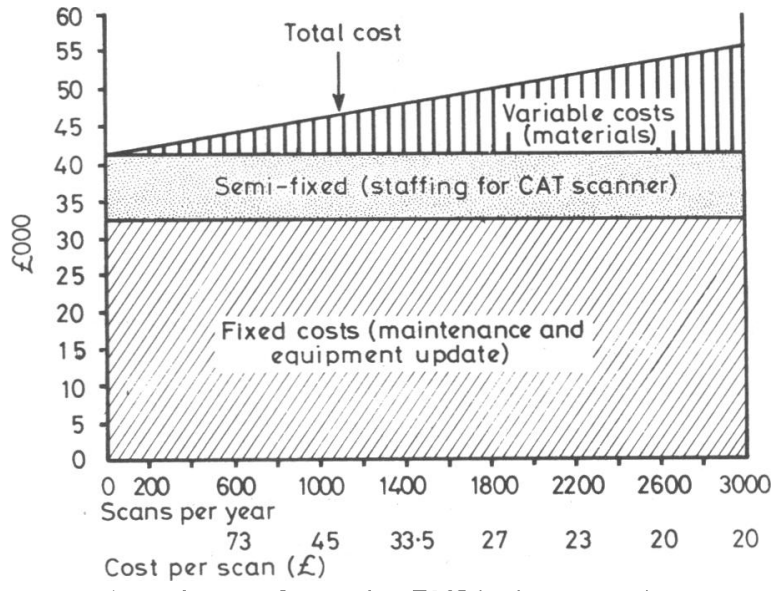

FIG 2-Annual costs of operating EMI brain scanner in 1977 at Brook General Hospital.

Purchasing and installing a CAT scanner-Each brain scanner is assumed to cost $f 190000$ and each brain-optimised general purpose scanner $£ 225000$. (These figures are the mid-point in the range of costs.) This equipment could be leased for around $27.5 \%$ of the original equipment cost. A full new suite of rooms for CAT scanning, including reception and records, may require up to 2000 square feet. But in the NHS conventional neuroradiology rooms can usually provide space for the scanner at no net cost in major building works. $£ 20000$ has been added to the equipment costs of each system to cover installation.

Consumables-The costs of computer tape, television reels, contrast media, Polaroid film have been well documented. SPRI figures have been used and converted into sterling; they will, if anything, be on the high side.

Maintenance costs-The experience of most CAT users is that annual maintenance charges run at about $8 \%$ of the original capita cost.

Staffing costs-The cost of staffing the options depends on $(a)$ the total number of units and their size and organisation, and $(b)$ the time taken for a scan under "standard" conditions. For the former the unit staffing levels at Frenchay were used ${ }^{1}$; and for the latter the workstudy-based man-hour per test figures quoted by SPRI, ${ }^{2}$ which are consistent with the usual clinical standards in UK brain scanning units.

Equipment update costs-CAT is a relatively new technology and the average time between signiticant modifications is only two years. Furthermore, although the practical economic life of conventional neuroradiology equipment is about 10 years, it is unlikely that the projected rapid improvement in CAT technology will allow a practica life of much beyond five years. Annual updating costs incurred by the investment in CAT scanning have been assumed to be $£ 10000$ per system, after two years.

Table V summarises the cost assumptions built into the option for additional deployment of scanners.*

These costs assume that each of the options can be implemented without major changes to existing buildings and facilities. This is by

TABLE $\mathrm{v}-$ Costs of scanner deployment option

\begin{tabular}{|c|c|c|c|}
\hline & & Options & \\
\hline & 1 & 2 & $3-5$ \\
\hline $\begin{array}{l}\text { No of additional scanners } \\
\text { No of scans per year } \\
\text { Costs ( }(\text { OO0): } \\
\text { Equipment and installation } \\
\text { Consumables per year } \\
\text { Maintenance per year } \\
\text { Staffing per year } \\
\text { Equipment update per year }\end{array}$ & $\begin{array}{r}2 \\
5300 \\
420 \\
25 \\
35 \\
60 \\
20\end{array}$ & $\begin{array}{r}2 \\
8100 \\
420 \\
25 \\
35 \\
60 \\
20\end{array}$ & $\begin{array}{r}5 \\
12650^{*} \\
1180 \\
40 \\
90 \\
90^{*} \\
30^{*}\end{array}$ \\
\hline
\end{tabular}

-Under options 3, 4, and $535 \%$ of available capacity in the new scanners outside neuroradiological units will be required for brain studies. Updating and staffing costs have been assessed pro rata for the scanners; but full equipment installation and maintenance costs have been included.

* A statistical appendix describing the calculations in more detail may be obtained from the authors. 
TABLE VI-Major economic factors affecting each option

\begin{tabular}{|c|c|c|c|c|c|c|c|}
\hline Option & $\begin{array}{l}\text { No of neurology } \\
\text { departments }\end{array}$ & $\begin{array}{l}\text { No of additional } \\
\text { scanners }\end{array}$ & $\begin{array}{l}\text { Hospital } \\
\text { closures }\end{array}$ & $\begin{array}{l}\text { New } \\
\text { building }\end{array}$ & $\begin{array}{l}\text { Rehabilitation of } \\
\text { old buildings }\end{array}$ & $\begin{array}{l}\text { Improved service } \\
\text { for head injuries }\end{array}$ & Comments \\
\hline 1 & 5 & 2 & No & Nil & Major & No & Major rehabilitation of and development of \\
\hline 2 & 2 & 2 & No & Minor & Major & No & $\begin{array}{l}\text { Minor new building project, major } \\
\text { rehabilitation and development of old }\end{array}$ \\
\hline 3 & 5 & 5 & No & Nil & Major & Yes & Major rehabilitation of and development of \\
\hline 4 & 4 & 5 & Yes & Moderate & Moderate & Yes & $\begin{array}{l}\text { Makes maximum use of existing sound } \\
\text { buildings which require some renovation, }\end{array}$ \\
\hline 5 & 5 & 5 & Yes & Major & Nil & Yes & $\begin{array}{l}\text { moderate new building project } \\
\text { Very major new building project, } \\
\text { complicated service reorganisation }\end{array}$ \\
\hline
\end{tabular}

no means always the case, particularly in cities with well-established hospitals and patterns of care. Indeed, option 2 will require additional facilities. The capital costs involved ( $£ 1 \mathrm{~m}$ or more) are of a different order of magnitude from the costs and potential savings from investing in scanners. Table VI summarises the main factors affecting implementation of each of the options.

\section{POTENTIAL SAVINGS FROM SCANNER INVESTMENT}

While the costs of investment in scanning are relatively easy to predict, at least at today's prices and wage levels, the extent of any savings that may be realised is much less certain. There are five possible sources of savings (table VII).

TABLE VII-Potential annual savings under scanner deployment options

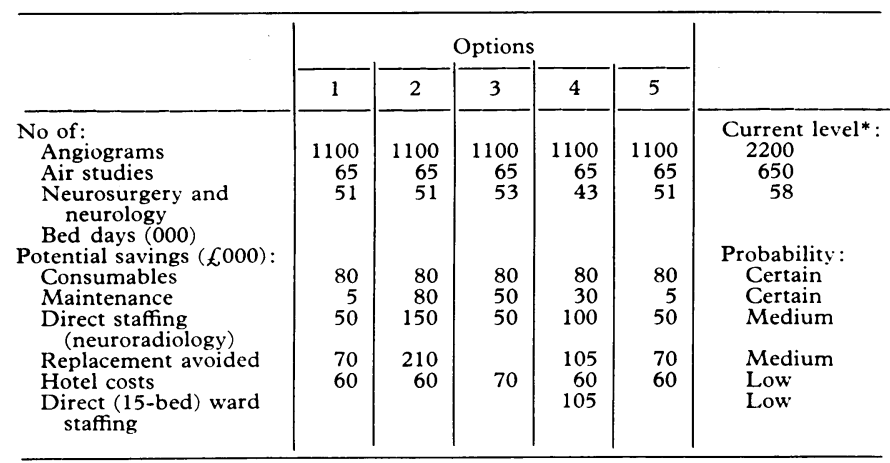

*In units directly affected by each option.

Consumable costs for angiography and pneumoencephalography will fall. Experience at the Brook General Hospital and elsewhere indicates that when a CAT scanner is available to neurosurgeons and neuroradiologists the number of angiograms will fall to half and air studies to around one-tenth of their former level in those specialist units with newly provided access to scanners. The potential savings in the cost of materials are substantial: the ratio of materials costs per test for angiography, pneumoencephalograpily, and CAT is about $11: 6: 1$. The main savings come from film, contrast media, and disposable items such as syringes.

Maintenance on existing neuroradiological equipment will cost less. Existing maintenance costs in the region are around $£ 140000$ a year, and annual savings of around $£ 25000$ a unit can be expected when units are closed (savings when scanners are introduced but existing departments remain will be modest, probably around $10^{\circ}{ }_{0}$ of present costs). Similarly, some existing conventional neuroradiological equipment will not need replacing: the current regional budget for such equipment is around $£ 350000$ a year. $\dagger$

Direct staffing costs for conventional neuroradiology will be lower. Under "standard" conditions there is a considerable difference in the man-hours required per test. For angiography, encephalography, and CAT scanning the ratio is about 4:9:1, including an allowance for anaesthetists and assistants. Because of the need to retain conventional neuroradiology centres at low utilisation, however, proportionate staff +One NHS region serving a population of 2.9 million earmarked $£ 1.15 \mathrm{~m}$ for replacement of all conventional $x$-ray and radiotherapy equipment, including linear accelerators. savings cannot be achieved. Potential savings in staff costs of $£ 60000$ a unit are possible when an existing neuroradiology unit is closed. Savings in units that remain open will be small, not more than $£ 10000$ a unit; and when staffing costs for operating scanners are taken into account there will be a net increase of perhaps $30^{\circ}$ o above pre-scanner levels.

Savings in neuroradiology space-Preliminary analysis of the space implications of the various options in the illustrative region suggests that space savings of up to 10000 square feet might be achieved. But the space is in relatively small units, often not suitable for high-grade use-for example as pathology laboratories-but only as low-grade storage or record rooms. As such it has a potential value of perhaps $£ 15-20$ per square foot. But since hospitals generally have more than enough space this saving is not included in the cost effectiveness evaluation that follows.

Reduction in hotel costs-In principle, the introduction of CAT scanning should reduce the total number of bed days required for any selected group of patients. Many more patients can be investigated as outpatients; days of recuperation after tests are reduced; and patients (particularly those admitted directly to neurosurgery units) can be operated on more quickly. But conclusions based on crude average length of stay or similar statistics are suspect, because of the difficulty of standardising the results for other variables, such as case mix and the effect of waiting lists on doctors' behaviour. Nevertheless, an analysis of length of stay in the Brook General Hospital confirmed general US experience: mean length of stay in 57 patients with tumours after the introduction of scanning was 11.2 days compared with 14.5 days in 1974 ; in 133 patients with vascular diseases mean stay was 11.7 days, compared with 15.9 days in 1974 . A reduction of $10-15 \%$ in length of stay may therefore be possible. It will be important to be certain that the apparent reduction is not due to more rapid transfer of patients to their local hospital from regional units, with no overall reduction in bed days.

The bed days released can be used to accept more patients and to provide greater flexibility-more empty beds for emergency cases. Alternatively, in the region taken as a whole, it may be possible to reduce the number of beds overall. The full direct staffing and hotel costs for an occupied bed are about $£ 10000$ a year, and if wards could be closed (or diverted to other uses) major savings would be possible.

Table VII summarises the potential savings associated with the scanner deployment options for the region. These are built into the cost evaluation that follows.

Clearly there is ample room to challenge the level of the assumed savings, and particularly the probabilities attached to each. They have been reviewed by knowledgeable observers of the NHS. The important point is that the savings must be realistically assessed.

\section{CALCULATING PRESENT VALUE OF EACH OPTION}

Using the cost and savings assumptions for each option, we calculated the cash flow for each year of the expected six-year life of the additional equipment, assuming that $(a)$ installation of the equipment would be phased over two years; $(b)$ in year 1 only half of the running costs would be incurred and half of the potential savings from installing the additional equipment realised; (c) all "certain" savings would be realised; $90 \%$ of high probability, $70^{\circ}{ }_{0}$ of medium probability, and $50^{\circ}$ of low probability savings were also included. The scanners were assumed to have no residual value at the end of year 6.

The net cash flow for each option was then adjusted for inflation, assumed to be $9 \%$ a year over the expected six years' life of the equipment and discounted at $13 \%$ a year, to reflect the costs of funds 
to the NHS. The results are shown in fig 3, which indicates that an investor who wanted to achieve a $13 \%$ return on any investment would be prepared to pay up to $£ 800000$ now to invest further in scanners along the lines of option 2 if he received the savings himself

The calculations set out above take no account of a number of the important related costs and savings that will arise in evaluating these options, including transfer and provision of buildings and facilities for related specialties on a new site; closure of an accident department; adaptation or rehabilitation of old buildings; new buildings and possibly hospital closure. Not every factor enters each option. But by any standards the sums of money involved are huge when set against the cost of a scanner. Any of these factors could transform the economic attractiveness of an option and therefore should affect the choice. For example, if the consequential costs of implementing option 2 exceed $£ 900000$ option 1 should be preferred economically. Of if the value of the improved service for head injuries in option 4 is considered to be worth more than $£ 430000$ over six years compared with option 1 the wider deployment of scanners would be preferred.

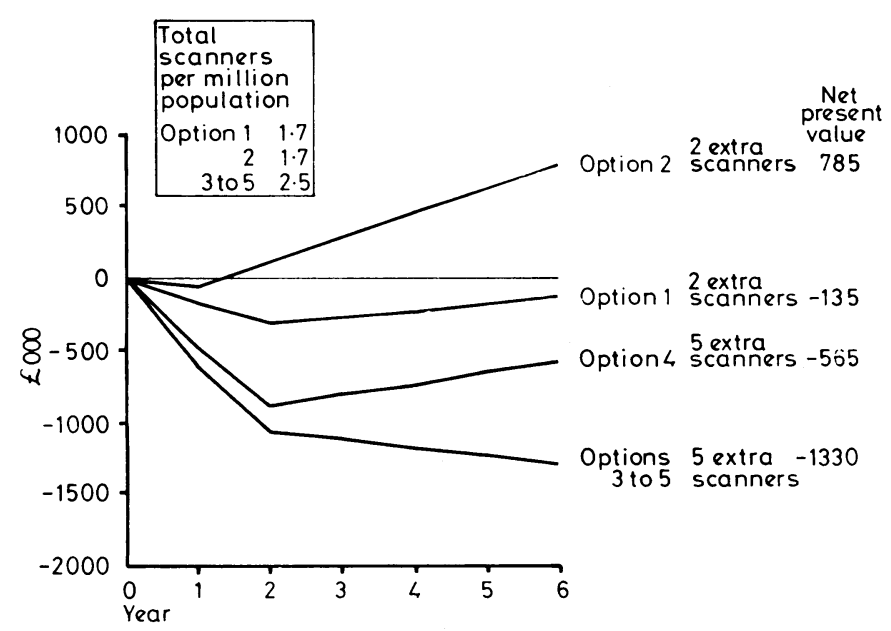

FIG 3-Net cash flow for each option adjusted for inflation $(9 \%$ a year for 6 years) and discounted at $13 \%$ a year, and net present value.

\section{Value of improved treatment}

The evaluation so far has taken no account of the clinical efficiency of brain scanners. It has been assumed that patient care is not affected and that all clinical decisions could be made equally well by using existing tests. A cost analysis that ignores the possibility that a clinical advance may also have value (profit and loss) is unsatisfactory. While this argument is open to challenge, it is potentially the most significant.

Some people have suggested that early diagnosis (using expensive techniques when required) will reduce future costs. Others assert that early diagnosis leads to meddlesome and unnecessary treatment, which may carry a risk of morbidity or death. For example, some clinicians believe that if the scanner were used to examine all patients with head injuries the advantage of the early detection and treatment of a significant extradural haematoma in saving lives of good quality would be more than offset by the cost of maintaining severely braindamaged patients with no hope of useful recovery. A study that was not primarily centred on the use of the scanner ${ }^{5}$ suggested that this latter fear is unfounded. There may be a net saving of good quality lives. This saving might have an important influence on which option is chosen.

The recent report of the Advisory Committee on Trunk Road Assessment, ${ }^{6}$ which has been accepted by the British Government, indicates that the net present value of avoiding one fatal road accident now built into the cost benefit analysis of different schemes is $£ 47300$. The committee recommends that this figure should be increased to at least $£ 60000$; the comparable figure used in Australia is $£ 78000$ (in 1976) and in Canada in 1975 it was $£ 66500$.
If one life is saved annually by each scanner and that life has a net present value of $£ 50000$ the economic attractiveness of the various options is transformed. Fig 4 shows the new net present values of the options. These values assume that each scanner is deployed, geographically, to provide equally effective access to head-injured patients. The options likely to show a positive net present value at six years are those in which scanners are more widely used and major changes in the service are implemented.

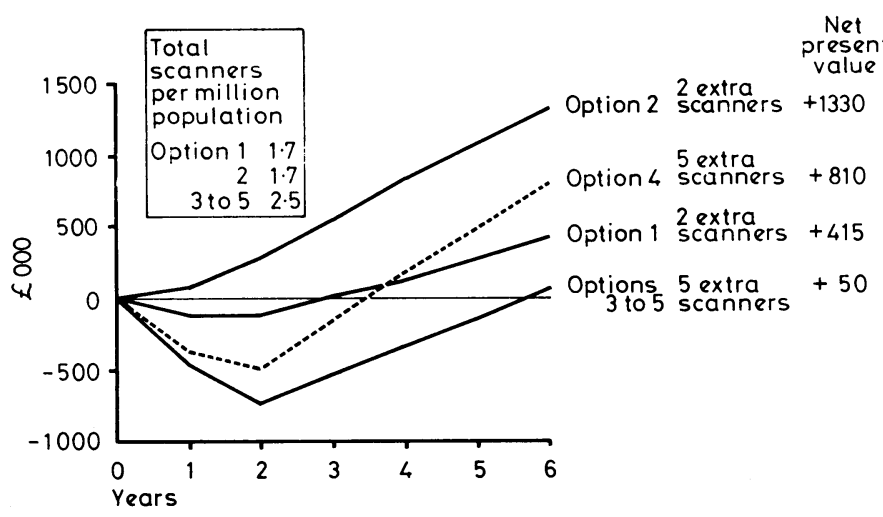

FIG 4-Net present value of options assuming that each scanner saved one life per year.

There are other advantages to making the scanners more widely available. Scanners located in accident units will have substantial spare capacity-perhaps as much as half in options 3-5. The "spare" half could be used for body studies at marginal additional costs, since the scanner will have already been justified and even have "paid" for itself on the basis of its cost efficacy in carrying out brain studies. This should provide the financial breathing space needed to establish the clinical efficacy and cost effectiveness of whole-body scanning.

\section{References}

1 Thomson, J L G, Health Trends, 1977, 9, 16

2 Jonesson, E, and Marke, L A, Health Care Management Review, 1977, 2, 37.

3 Wortzman, G, Holgate, R C, and Morgan, P P, Radiology, 1975, 117, 75.

${ }^{4} C T$ in Perspective: Diagnostic Efficacy and Health Care Implementation. Northbrook, Illinois, EMI Medical Inc, 1977.

5 Becker, D P, et al, fournal of Neurosurgery, 1977, 47, 491.

6 Advisory Committee on Trunk Road Assessment, Report. London, HMSO, 1978.

(Accepted 26 fuly 1978)

What are the present views on the treatment and prognosis of parapsoriasis?

Parapsoriasis is a chronic scaly dermatosis of unknown aetiology, the lesions of which are fixed in position. It has a progressive course leading ultimately to mycosis fungoides, although the exact proportion developing this condition is unknown. The time to development of mycosis fungoides is long-usually 15 years or so-and is quicker when there is associated poikiloderma (atrophy, telangiectasia, and pigmentation). The clinical features of this stage are infiltration of the plaques, and histologically there are lymphocytes in the epidermis and mycosis fungoides cells, which are thought to be $T$ cells with polyploidy; the increased mass of DNA explains their large crenate nuclei. There is no satisfactory treatment for parapsoriasis: ultraviolet rays and corticosteroids help a little, and it remains to be seen whether psoralens and long-wavelength ultraviolet rays (PUVA) are effective, and if so whether this will prevent mycosis fungoides developing. 